\title{
A WebGIS Decision Support System for Management of Abandoned Mines
}

\author{
Ranka Stanković *, Nikola Vulović, Nikola Lilić, Ivan Obradović, Radule Tošović \\ and Milica Pešić-Georgiadis
}

Faculty of Mining and Geology, University of Belgrade, Belgrade 11000, Serbia; nikola.vulovic@rgf.bg.ac.rs (N.V.); nikola.lilic@rgf.bg.ac.rs (N.L.); ivan.obradovic@rgf.bg.ac.rs (I.O.);

radule.tosovic@rgf.bg.ac.rs (R.T.); milica.pesic@rgf.bg.ac.rs (M.P.-G.)

* Correspondence: ranka.stankovic@rgf.bg.ac.rs; Tel.: +381-607-009-992

Academic Editor: Peter V. Schaeffer

Received: 26 May 2016; Accepted: 12 July 2016; Published: 21 July 2016

\begin{abstract}
This paper presents the development of a WebGIS application aimed at providing safe and reliable data needed for reclamation of abandoned mines in national parks and other protected areas in Vojvodina in compliance with existing legal regulations. The geodatabase model for this application has been developed using UML and the CASE tool Microsoft Visio featuring an interface with ArcGIS. The WebGIS application was developed using GeoServer, an open source tool in the Java programming language, with integrated PostgreSQL DB and the possibility of generating and publishing WMS, WFS and KML services. The WebGIS application is publicly available, based on an appropriate central database, which for the first time encompasses all available data on abandoned mines in Vojvodina, and as such may serve as a model for similar databases on the territory of the Republic of Serbia.
\end{abstract}

Keywords: WebGIS; geodatabase; abandoned mines; mine reclamation

\section{Introduction}

Problems of development of cadastre of abandoned mines can be perceived as an important function of modern management of mineral resources (which is part of the broader management of natural resources), environmental management and management within state bodies.

The modern concept of management of mineral resources in Serbia includes comprehensive registration and monitoring of mineral resources at various stages of their exploitation and processing. From the viewpoint of economic geology three specific phases can be observed related to the exploitation process, namely: (a) mineral resources before exploitation; (b) mineral resources during exploitation; and (c) mineral resources after exploitation. The issue of abandoned mines belongs to the third phase, characterized by specific features related to expert knowledge in geology and mining, as well as in urban planning, spatial planning, agriculture, hydrology, ecology, safety and the like.

From the standpoint of economic geology, in the case of abandoned mines, two distinct groups can be singled out, namely: (a) abandoned mines with remaining reserves of mineral resources; and (b) abandoned mines with depleted reserves. Mines from the first group are especially interesting as objects for analysis when there is entrepreneurial and economic interest in their reactivation and evaluation of remaining reserves. As for those from the second group, they are of interest only as sites for remediation and reclamation. Regardless of the group and the state of reserves, data collection is needed, as well as their systematization and representation in appropriate databases. From the legislative and legal point of view two subgroups can be distinguished within the first group, namely: (a) abandoned mines with legal deposits, for which geological research projects, studies on reserves and mining projects exist; and (b) abandoned mines where illegal mining took place. Available data for the 
first subgroup are more reliable and comprehensive, given the existence of initial geological-economic information about these facilities. Thus the current state of these facilities can be compared with existing data, followed by an expert assessment of the current situation. For the other subgroup only the expert assessment of the current situation can be carried out, as a basis for further action.

Analysis and solutions of problems of abandoned mines is also important for management of natural resources beyond the mineral resources domain. This includes, in particular: (a) urban development, namely its impact on the environment, especially the wider area around the open pit; (b) spatial planning of the same wider area within reclamation; (c) the soil and its relationship with agricultural activities in the wider area, which is particularly important for Vojvodina, as an agricultural region; and (d) water resources, both surface water and groundwater in the wider area, including hydrogeological and hydro geothermal resources.

From the standpoint of environmental management, two distinct groups of abandoned mines can be distinguished, namely: (a) abandoned mines within national parks or protected areas; (b) abandoned mines outside these protected zones or areas. Special restrictions exist for the first group in the form of prescribed measures and activities relevant to national parks or protected areas, which is of importance in solving the pending issues of remediation and reclamation. In the territory of Vojvodina, which has been the subject of activities within the project reported in this paper, abandoned mines from both groups exist. Regarding the environmental consequences of the presence of abandoned mines, the following should be taken into account: (a) the physical degradation of the surface, relief and environment that took place, especially in the case of improper and unplanned exploitation; (b) the impact of mineral substances present in the exploited deposits on environmental features; and (c) the impact of various municipal waste materials, which were deposited without authorization, organization, preparation and planning in the area of abandoned mines. From the geological point of view, it is favorable that in the area in Vojvodina there are no mines of metal mineral resources, which usually have a more or less pronounced impact on the environment. Solving the problem of abandoned mines is also important for improvement of the environmental situation of wider areas, regardless of the degree of impact.

There is some important potential for using abandoned mines for energy generation. One of them is generation of heating and cooling energy from the natural heat contained in the mine water. Geothermal energy systems using heat pumps to extract this heat can be used to offer local employment and energy resilience to the surrounding communities [1]. Abandoned mine methane (AMM) can also be recovered from closed coal mines and used for producing thermal and electrical energy, especially immediately after a mine's closure, while at the same time reducing atmospheric emissions of methane [2]. A study by University of Minnesota Duluth's Natural Resources Research Institute shows that the water-laden pits of abandoned mines have the potential to store wind energy by a pumped-hydro storage process which would use excess late-night wind energy to pump water uphill from the pits to a higher-elevation holding pond. During the day, when electricity demand goes up, the flow is reversed and energy captured in hydro turbines. According to this study, for every 100 megawatts used to pump the water upward during night, the plant generates nearly 80 megawatts through the turbines in daytime [3,4]. From the standpoint of management within state institutions, current data on abandoned mines are important for the implementation of the relevant activities within their competence. In particular, this includes the legislative and legal, as well as control and monitoring activities related to geological exploration and exploitation, but also the legal obligation of reclamation. There is also a specific indirect importance in obtaining baseline data as part of the implementation of appropriate guidelines of mineral strategy, mineral policy and the concept of sustainable development in the mineral economy of Vojvodina, as an integral part of the mineral economy of Serbia. Potentials for energy generation from abandoned mines in Vojvodina should also be taken into consideration.

Finally, it is necessary to point out the special economic importance of establishing the cadastre of abandoned mines from several aspects, namely: (a) funds savings within the comprehensive planning 
of further development of the broader domain, on the basis of different types of complex data, instead of partial unharmonized individual projects and plans with contradictory solutions; (b) funds savings for the work on remediation and reclamation at the expense of the state, by resolution of ownership issues related to the land in question; (c) realistic planning of the necessary financial resources for remediation and reclamation tasks; (d) generating income based on fees for the use of data from the abandoned mines registry by interested business entities and individuals; and (e) facilitating economic planning of sustainable development of Vojvodina, as a compatible part of sustainable development of Serbia [5].

\section{Results}

The "Cadastre of Abandoned Mines in the Territory of AP Vojvodina" project was developed at Faculty of Mining and Geology, University of Belgrade. The project activities preformed within the development of the cadastre of abandoned mines in Vojvodina and the accompanying WebGIS application were complex and multidisciplinary, involving a team of experts from the geological, mining, economic, ecologic, informatics, mathematics and other domains. Special attention was given to securing a high level and quality of project work, both regarding the quality of content, namely data and information, but also regarding the quality of structural relations among data, as well as quality of user interface featuring easy and simple search and display od structured data.

Development of the software solution was compliant with recommendations related to spatial data infrastructure (SDI), which implements a framework of geographic data, metadata, users and tools that are interactively connected in order to use spatial data in an efficient and flexible way [6].

\subsection{WebGIS}

The cadastre of abandoned mines Web GIS application KaNaKov is publicly available for search and browse of relevant geospatial and attribute data [7]. The application supports searches in both the Cyrillic and Latin alphabet, with the possibility of selecting different themes, and features a user friendly interface, in English and Serbian (Cyrillic and Latin alphabet), for various types of devices: tablet, laptop or desktop computers (Figure 1). The main page of the cadastre of abandoned mines of Vojvodina shows the application home page, where the central, and the largest part of the screen displays a map of the abandoned mines. The base layer can optionally be either from one of the OpenStreetMap [8,9] or ArcGis maps [10]. On top of the base layer, which is displayed using OpenStreet maps two additional layers are shown: polygons singled out by remote sensing methods and polygons resulting from the analysis of exploitation authorizations, requests for reclamation and site visits.

The left side of the web page consists of four tabs: the list of layers, the panel for search, the legend, and user manual. Figure 2 shows details from the four tabs: Selection of visible layers (a), Search (b), Legend (c) and Manual (d). The list for layer selection has two distinct groups: one for the base layer and the other for thematic layers. Apart from choosing between the two web map service providers: ArcGIS or OpenStreetMap, within the first group the base layer can be selected from several different types: topo map, street map, satellite imagery or road, depending on the point of view and interest in abandoned mine sites. Namely, it is possible to select Simple or Road Open Street Maps or several types of ArcGIS layers, such as World Topo, World Street or World Imagery Map. The second group consists of thematic layers: abandoned mines, remote sensing results, permits and demands for exploitations. The tab Legend explains the map symbolization of spatial data.

The panel for search provides for locating abandoned mines that match the user query. Users can search by abandoned mines index, name of the object or settlement or district where abandoned mines are located. Search results are displayed in a pop-up window on the map. For each search result, detailed information about the selected object can be viewed on a separate web page. The multimedia gallery of abandoned mine sites and the map can be zoomed in on a selected mining area. For each mine within the initial map basic information can be viewed in a pop-up window, with a link to detailed data. 


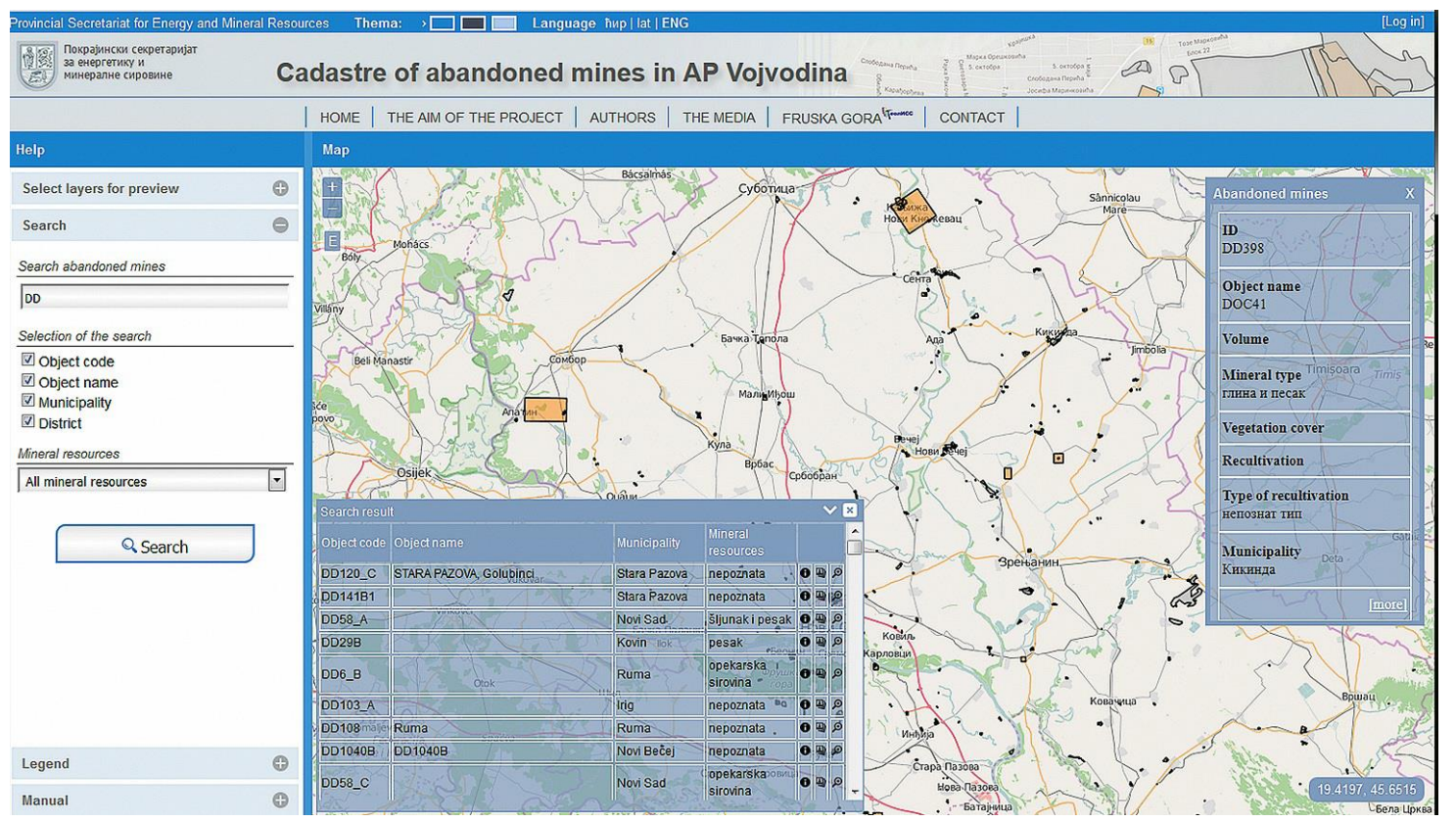

Figure 1. Main page of the Cadastre of Abandoned Mines of Vojvodina.

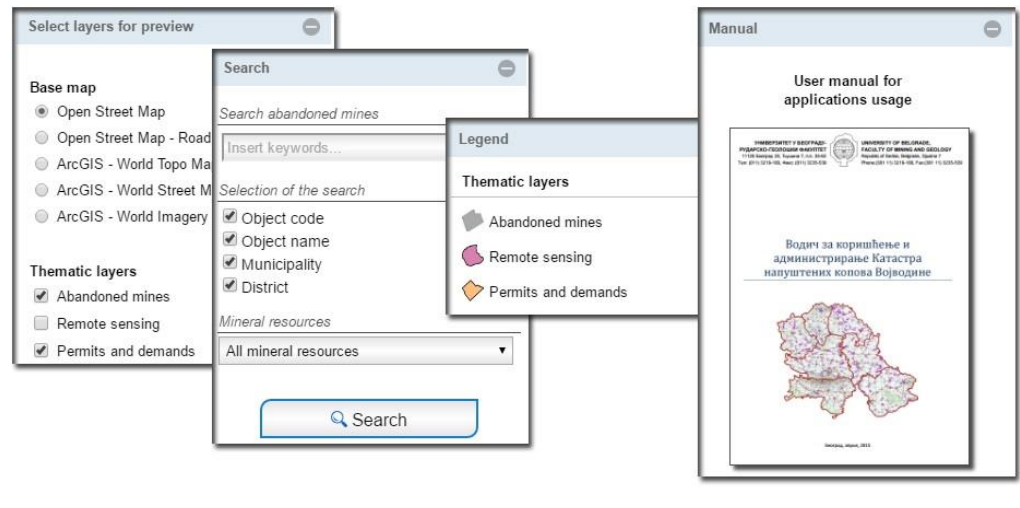

(a)

(b)

(c)

(d)

Figure 2. Selection of (a) visible layers; (b) Search; (c) Legend and (d) Manual.

Detailed information about a mine site are shown in a separate page and are grouped into the following sections: general data, properties, registry, owner (stakeholder) and multimedia. A small dynamic map of the surrounding area of the selected mine site with a zoom in possibility is shown with textual and numerical data. Further possibilities for data management and analysis are accessible only for authorized users, who can login in the site home page to proceed with full access. Authorized users include administrators of the system, who manage the meta data and system preferences data, and editors, who have the option of editing data related to mine sites and companies, but not data related to user accounts and data dictionary.

\subsection{Web Application for Non-Spatial (Attribute) Data}

For the non-spatial data, authorized users can use the protected part of the application on the following pages: Users, Industrial organizations, Registries, Abandoned facilities, Directories, Statistics, Reports. Handling of all datasets takes place in a similar way: the first page features a tabular representation of the data set with the possibility of search, that is, filtering according to given criteria. The level of access to data and the possibilities for editing depend on privileges that are 
assigned to a particular user. For each user, the system keeps track of the user name, first name, surname, date of activation of the user account and the date of last log-in, status, and the role in the system: administrator, editor, reader. The system records each login and activity information to identify responsibility for entered data and general system usage.

\subsubsection{Stakeholder Data}

The application module dedicated to administration of data related to companies, institutions and organizations i.e., stakeholders and beneficiaries, in tabular and detailed form, is presented in Figure 3. Data management is user friendly and includes various types of filtering and selection with flexible output format and preview. All available and relevant data are stored in a database, such as, formal name of company in the Serbian Business Registers Agency (APR), commonly used name of company, location, contact person, addresses, phones, emails, web site URL, municipality and administrative area, tax identification number, etc. Domain control for specific data is based on a common vocabulary, integrated in the database and application. All data related to one company, like permits, field visit records, multimedia, described and contoured area, remote sensing data, can be retrieved and displayed, both on the map and in the form of a web page and report.

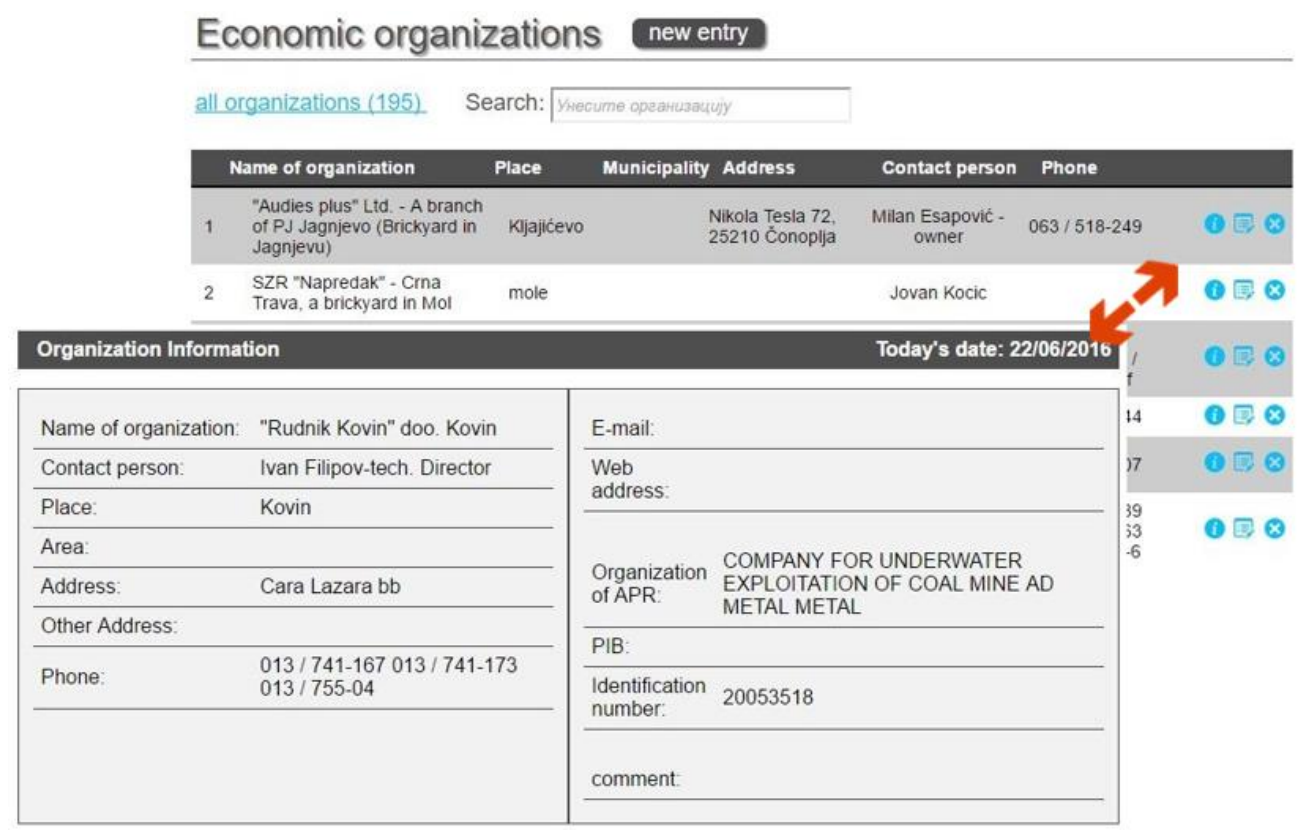

Figure 3. Data management for stakeholder data.

\subsubsection{Exploitation Permit Data}

The registry of mine sites and facilities includes the following data related to exploitation permits: title, city, municipality, county, address, location, while the type is selected from a predefined list of terms: surface mine, underground mine, processing, tailings, maintenance workshop, etc. If available, cadastral parcel or parcels and information on the rights owner are registered. All existing permits and related documentation in this area can be attached, with the area (polygon) that indicates the approved exploitation area or the area for which the request for reclamation was filed. While data within the entire project were calculated automatically wherever possible, additional data, such as distance to the nearest town, approved area or local recipient water can optionally be entered manually.

Field values for type of mineral resource are domain controlled, so the user can only select from the list of pre-defined values. The same is true for status, which can be: active, abandoned, unknown, temporary suspension of work, permanent suspension of work. Figure 4 shows the panel with general data on the register of abandoned mines. 


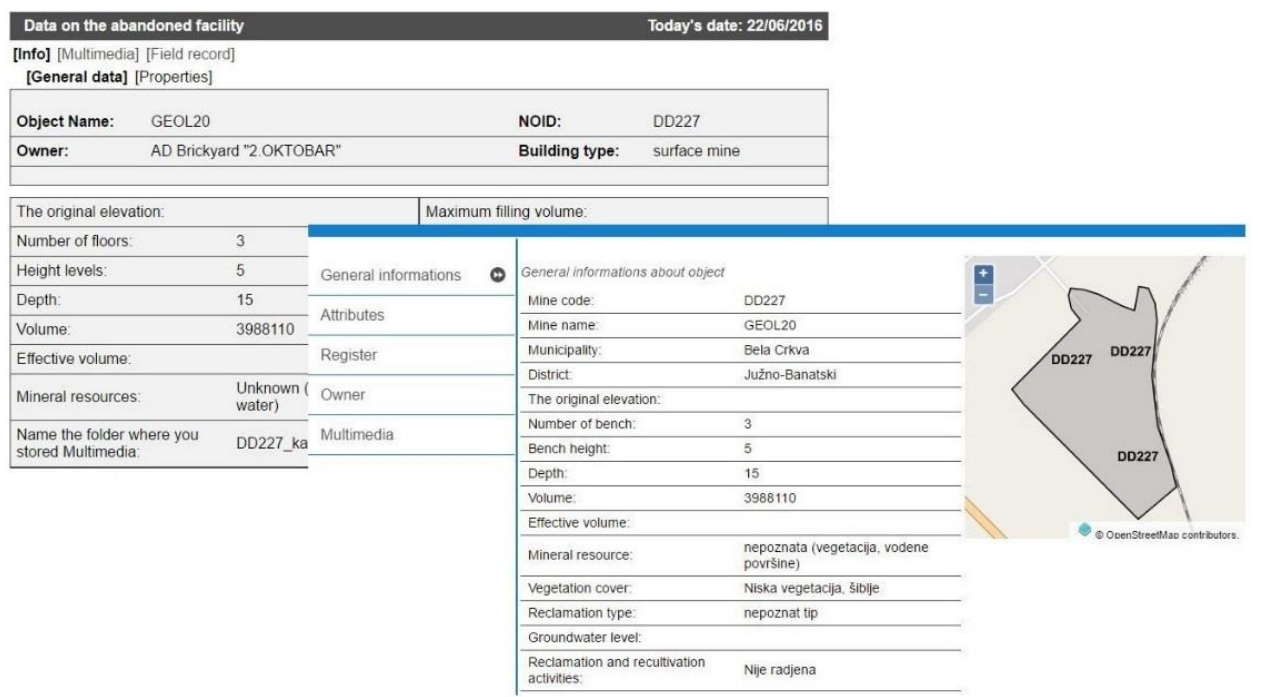

Figure 4. Panel with general data on the register of abandoned mines.

\subsubsection{Abandoned Mine Waste Sites Data}

Administration of abandoned mines includes the entry of the following data: general information, information on mine features, a photo of the mine and, if available, mine coordinates. The panel on the left side of Figure 5 shows basic information for the abandoned mine on the location Gaj within the Municipality of Kovin, while the right side represents the multimedia data panel for the same mine.

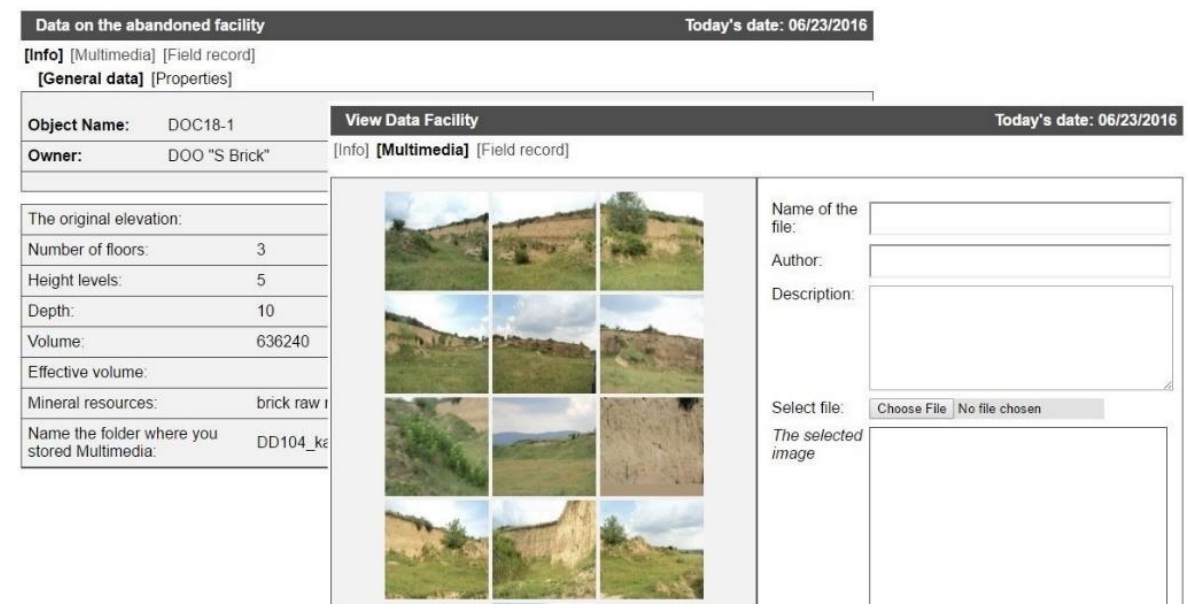

Figure 5. The panels showing basic information and multimedia data fora mine.

\subsection{Reporting and Data Analysis}

Within the reporting system the following reports are available:

- Reports giving data on individual abandoned mines (general data, properties, registry, rights owner, coordinates, assessments)

- Register of abandoned mines by municipalities (city, locality, cadastral parcel, rights owner, assessments...)

- Reports on abandoned mines with assessments and values of the criteria on which assessments were made

- Reports on the ranking of abandoned mines with assessments

- List of commercial organizations, their registers and related mines. 
The user can select to print a single record of an abandoned facility or records about all abandoned mining facilities in the municipality, district or national park. Statistics of mining facilities and results of remote sensing by property type, by district, municipality, by mineral resource or method of registration and the like are also available. Apart from general statistics related to polygons obtained by remote sensing and classified by property type, by district and by municipality, the analytical part of the application report offers data on usage: logins, data entry and export analytics [11]. Statistical reports provide an overview of the use of the application on the basis of log data (logons) and data entry, as well as the number of visits of the site using Google analytics. A system for reporting problems in system operation and review of frequently asked questions is also implemented [12].

\subsection{The Classification Method of Abandoned Mines}

\subsubsection{Analytic Hierarchy Process}

The Analytic Hierarchy Process (AHP) method used within this project is considered to be one of the most commonly used methods for multi-criteria decision making. The method of analytical hierarchy process is commonly used in the analysis of decision-making as well as in decision-making itself when complex problems encompassing goals, criteria, sub-criteria and alternatives are solved. The method was devised in the 1970s by Saaty [13]. From the methodological point of view, AHP is a multi-criteria technique based on the decomposition of a complex problems into a hierarchy. Decision making is based on evaluation of selected work activities and the application of matrix calculus, thereby alleviating subjective assessments of evaluators. The goal is at the top of the hierarchy, while the criteria, sub-criteria and alternatives are at lower levels. AHP has so far been applied in a variety of areas where decisions are of great importance and where decision makers readily choose a qualified and reliable advisor while pondering the alternatives and determining their effects in relation to the goals set.

Application of AHP methods in environmental protection system modelling provides for ranking of work activities, statuses, environmental and other factors taking into account the priorities related to remediation and reclamation within a specific energy complex.

\subsubsection{The Decision Criteria}

The criteria for evaluation and ranking of abandoned sites were, for the purposes of this project, grouped into the following groups: environmental protection, geological factors, sociological factors, technical and technological factors. Furthermore, each group of criteria was divided into individual criteria, and marks from 0 to 100 were assigned to each criterion, where 100 marks the highest and 0 the lowest priority for remediation. For the environmental protection group, the following factors were selected as the most important: type of protected area, land use, distance from watercourse, and distance from protected areas.

Among geological factors analyzed and evaluated were geological structure and vulnerability of groundwater. The source for assessing the vulnerability of groundwater was the map of groundwater vulnerability of Serbia [14], that integrates a number of factors: the slope of the terrain and its impact on infiltration, type of soil and vegetation cover, the thickness of the superficial layer, geological i.e., hydrogeological characteristics of the terrain and the level of groundwater.

Sociological factors are the number of inhabitants in a radius of $500 \mathrm{~m}, 1000 \mathrm{~m}$, and $2000 \mathrm{~m}$, and distance from settlements. All input values were calculated automatically from previously prepared vector maps, using various types of geoprocessing tools. Python programing language was mostly used for geoprocessing and supporting calculations.

The most important technical and technological factors: degraded area, volume of open pit, type of mineral resource, remediation type, type of mining site or facility, legal and working status, and type of ownership. 
Appropriate formulas were implemented in the software solution and the related calculation varies from simple to complex. As an example, we present simple formulas for score mapping to the range $0-100$ for quantitative variables, such as degraded surfaces area, waterway distance and population in the range of $500 \mathrm{~m}$ :

Surface_Score $=(\mathrm{P}-\min ) \times 100 /(\max -\min )$, where $\mathrm{P}$ is the degraded abandoned area of the current site, $\min / \max$ are minimal and maximal value for degraded abandoned area in the dataset;

Waterway_Distance_Score $=(100-(\mathrm{D}-\mathrm{min})) \times 100 /(\max -\min )$, where $\mathrm{D}$ is the distance of the mine site from the nearest waterway (river, lake, stream), $\mathrm{min} / \mathrm{max}$ are minimal and maximal distances in the dataset;

Population_500m_Score $=$ Pop $\times 100 /$ max $\_500 \mathrm{~m}$., Pop is the population living in diameter of $500 \mathrm{~m}$ from the current site, max_500 $\mathrm{m}$ is maximal population at a $500 \mathrm{~m}$ distance from a site in the dataset.

For the qualitative variables the score is mapped using a metadata dictionary, like for example for groundwater vulnerability: very high 100, high 80, medium high 60, medium 40, low, 20, very low 0 . The complete list of qualitative variables mapping is available in [15]. Authorized users can access and modify parameters of decision criteria, which adds more flexibility to the system.

\subsubsection{Weight Coefficients}

Bearing in mind that the influence of individual factors, i.e., criteria is different, relative assessments by pairs of attributes at a hierarchical level were made, for all levels of the entire hierarchy. The tables below give the final result.

The verification of consistency ratio (CR) of the AHP model was defined by Sati [16] as: $\mathrm{CR}=\mathrm{CI} / \mathrm{RI}$, where $\mathrm{CI}$ represents the consistency index and RI the random consistency index.

The consistency index is calculated as: $\mathrm{CI}=\left(\lambda_{\max }-n\right) / n-1$, where $\lambda_{\max }$ represents the largest matrix eigenvalue, and $n$ the number of factors [17]. The random consistency index RI is a table value empirically defined by Sati, which depends on the number of factors within the AHP analysis.

If CR $<0.1(10 \%)$ the model is consistent. According to Sati a deviation of CR up to $0.3(30 \%)$ is tolerated, but if $\mathrm{CR}>0.3(30 \%)$ a correction of the model is necessary.

Figure 6 shows the factors taken into account when ranking abandoned mines by priority of reclamation. The first column is the name of the factor, the second is the weight coefficient within the group of factors, and the third the final weight coefficient. The sum of all final weights is equal to one.

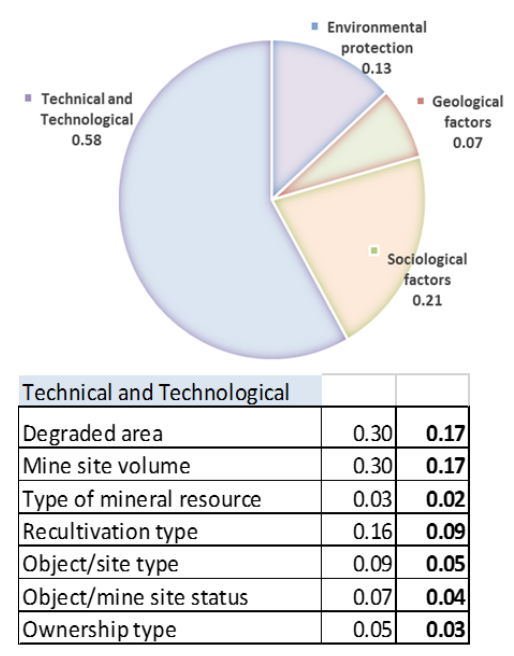

\begin{tabular}{|l|l|l|}
\hline Environmental protection & \multicolumn{1}{|l|}{} & \\
\hline Protected area & 0.22 & $\mathbf{0 . 0 3}$ \\
\hline Land use & 0.07 & $\mathbf{0 . 0 1}$ \\
\hline Waterways vicinity & 0.53 & $\mathbf{0 . 0 7}$ \\
\hline Protected area vicinity & 0.18 & $\mathbf{0 . 0 2}$ \\
\hline
\end{tabular}

\begin{tabular}{|c|c|c|}
\hline Geological factors & & \\
\hline Groundwater vulnerability & 1.00 & 0.07 \\
\hline
\end{tabular}

Figure 6. The weight coefficients.

Graphical illustration of the impact of individual factors in the overall assessment is given in Figure 7, where the coefficients are converted into percentages, with their total sum of $100 \%$. 


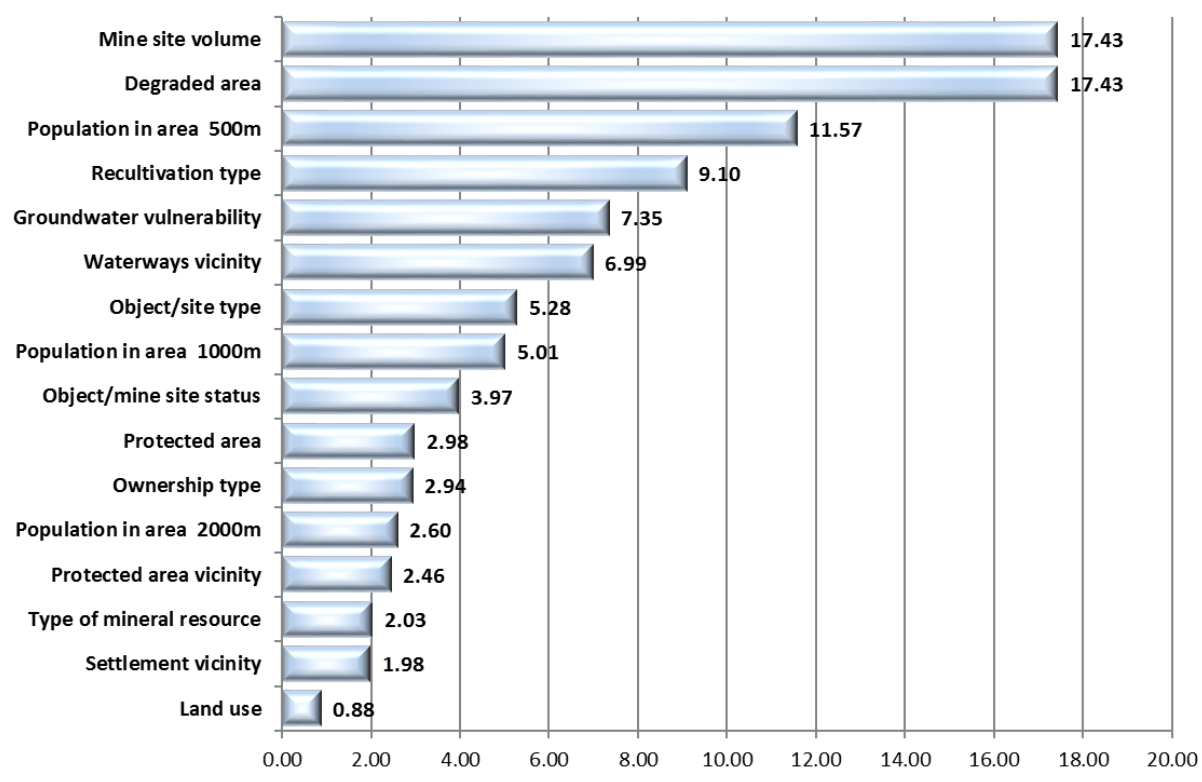

Figure 7. The impact of individual criteria in the total assessment.

\section{Discussion}

\subsection{International Experience}

Development of the database of the Cadastre of Abandoned Mines has been harmonized with existing international and European trends and standards (ISO 19115 and ISO 19119) [18]. With the adoption of Directive INSPIRE 2007/2/EC [19] by the European Parliament and the Council of Europe in European Union member countries, the infrastructure was established for spatial information records with the aim of improving environmental policy, that is policies and actions that have an impact on the environment. Emphasis is placed on interoperability in terms of availability of data related to the environment. Interoperability within INSPIRE implies the possibility of combining spatial data and web services from various sources throughout the European Union in a consistent way without specific human or hardware requirements, relying on EN ISO 19115 and EN ISO 19119.

There are also some relevant results in the USA. For example, The GeoMine geoportal supports the decision-making process in relation to activities related to surface coal mining by improving access to data, timely dissemination of data and understanding of geospatial data on different scales and at different levels [20].

The Abandoned Mine Land Inventory System (e-AMLIS) includes information on abandoned mines that are in need of remediation, and the mines which were subject to reclamation, that is, where the remediation process was completed [21].

U.S. Geoscience Information Network, USGIN is the federal framework for the exchange of information using free and open source technology that enables connection to similarly configured data exchange networks. This approach offers a long-term solution for the storage and exchange of data without commercial software. USGIN makes available, connects and opens the data related to the earth sciences [22].

The aim of the Upper Midwest Environmental Sciences Center-Ohio Valley Abandoned Mine Lands Study was to provide a central location for accessing and obtaining GIS spatial data needed for different aspects of the study of the terrain of abandoned mines and/or their remediation. These data include: basic data, hydrogeology, biology, geology and mining as well as specific information related to the terrain of abandoned mines [23].

Spatial data in the aforementioned study on terrain of abandoned mines as well as data concerning the remediation of this terrain were generally available. However, databases of geographic information 
systems were often incoherent and/or incomplete for targeted use. A central repository for regional GIS spatial data was necessary in order to facilitate the preparation of a study as well as efficient locating of personnel and resources during the remediation of sites and abandoned mines themselves.

\subsection{Serbian Practice}

The Law on Mining and Geological Exploration ("The Official Gazette RS", No. 101/2015) of 2015 states that "The Ministry shall keep a special register of documents on abandoned mines and mining facilities, as well as the records of mines and mining facilities subject to remediation and reclamation". In the mining waste fields cadastre the following data are entered: the limits of the mining waste field, the carrier of exploration and/or exploitation or economic entity that produces mining waste, the economic entity which is the operator of mining waste, the characterization and categorization of mining waste landfills within the mining waste field, as well as other data related to the management of mining waste. In the cadastre of abandoned mines and mining facilities data on the position and status of these mines and mine facilities are entered, as well as data on implemented measures for remediation and reclamation [24].

One of the requirements in developing the KaNaKov system was to integrate it with the existing GIS application GeolIEP for management of exploration and exploitation permits and works in the mineral resources field. GeolIEP represents a basis for archiving and efficient handling of vector, raster and related thematic alphanumeric content in one place, as well as efficient management and usage of mineral resources. The use of GeolIEP results in cost reduction in data storage and archiving and accessibility of data to a wider circle of users. The system is implemented within the ESRI ArcGIS technology framework as an ArcMap net extension that supports distributed user access to manipulation of spatial and alphanumeric data, issuing of permits, visualization of spatial data, generating of a cadastre of exploratory and exploited areas, data export, as well as web search and visualization [25].

With regard to the objective and purpose of the research, the method of remote sensing was used to extract potential areas of anthropogenic impacts on the territory of Vojvodina, using morphological indicators of anthropogenic influence as the main criteria. Complying with the investors' instructions, all the anthropogenic changes in the morphology of the terrain have been detected and outlined, regardless of their area and the time of occurrence. According to the detection criteria, different types of surface changes were outlined, as follows: wide area affected by degradation, abandoned old mines, landfills (industrial or municipal waste), areas with industrial plants, mines with active waste dumps and borrow pits.

Anthropogenic influences on a terrain such as those from the group of degraded areas can be dated from different historical periods and there is a possibility that there could be an archaeological interest. Therefore, this database can be of multiple importance, from a wide range of different scientific disciplines, i.e., archaeology.

In Serbia there is currently no comprehensive spatial database of archaeological sites; so, the cadastre of abandoned mines could be a good starting point for this. Furthermore, integration (centralization) of all information about archaeological sites with the cadastre of abandoned mines on the territory of AP Vojvodina could be essential for the future strategic planning of the geological and archaeological exploration of this area.

Under the framework of the IPA Program (The Instrument for Pre-accession Assistance), a new project "Cadastre of Mining Waste" is being developed, which will support the Government of Serbia in achieving its strategic goal of accession to the European Union, and for improving the environment, by assisting in the implementation of this element of the National Environmental Approximation Strategy of Serbia to guide the process of bringing the country into line with the EU environmental acquis. The project "Cadastre of Abandoned Mines in the Autonomous Province of Vojvodina" is singled out as the key project of reference in the procurement procedure for this new project. Hence the 
new project will have to be closely linked and compatible with KaNaKov to avoid duplication of resources and to ensure that full synergies are achieved.

\section{Materials and Methods}

\subsection{Geodatabase Model}

The geodatabase model was developed using Unified Modeling Language (UML) and Computer-Aided Software Engineering (CASE) tool Microsoft Visio (Microsoft Corporation: Redmond, WA, USA), which has a developed integration feature with ArcGIS. Figure 8 shows part of the logical data model with basic classes of the registry of abandoned facilities, which inherit abstract ESRI classes Feature and Object. The central place is the abandoned_facility_registry class, which maps the data on a degraded area, and defines the rights owner by the relation to the class company. Like other attribute classes, it inherits the abstract class generic_attributes and receives attributes of the primary key, relations to the metadata, comment, and record author classes.

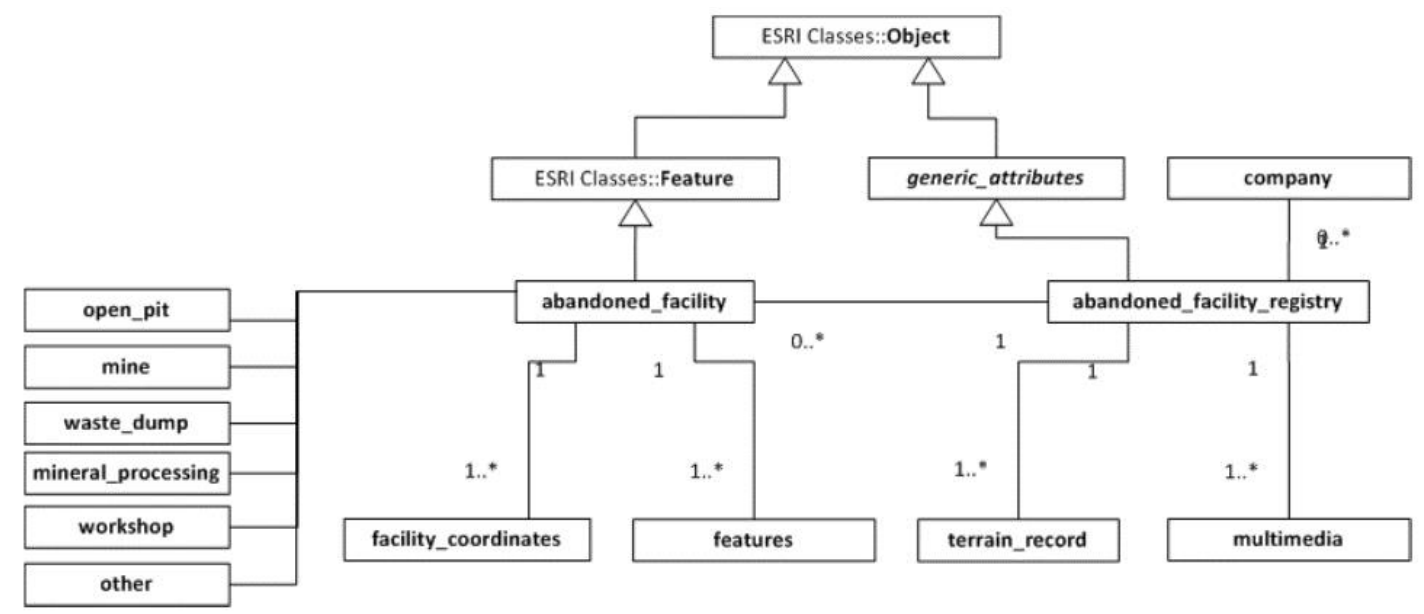

Figure 8. Characteristic part of the conceptual model. Note: $1 . .^{*}$ stands for relation 1 to many.

The class company comprises contact details of all rights owners in the database, while the class terrain_record models notes taken during field visits. The class multimedia is intended for photos and video records collected during field visits. The spatial polygonal class abandoned_facility describes the geometric parameters of the degraded area: contour, surface, average bench heights, the overall depth of the pit, volume, as well as general data collected during the field visit related to reclamation, water level (whether the mine is above, below, or above and below water level), as well as the site, for example, a pit, a landfill, workshop or plant. Figure 8 shows part of the conceptual data model. More details about model are available in [15] logical data model of Kanakov.

\subsection{Development Environment}

The relational database management system used was PostgreSQL (The PostgreSQL Global Development Group: Red Hat Inc., Portland, OR, USA) with the PostGIS extension (Open Source Geospatial Foundation (OSGeo): Beaverton, OR, United States) to support spatial data. GeoServer (OSGeo) was used for generating and publishing Web Map Service (WMS) and Web Feature Service (WFS), Keyhole Markup Language (KML) and everything else needed to create a web GIS application. GeoServer is an open source tool designed in Java which enables users to serve spatial data. Its primary role is to serve as connection in an open spatial data infrastructure (SDI). Figure 9 presents some of the published WMS services for web mapping of abandoned mines, polygons obtained by remote sensing and permits and demands for exploitation. Using the open standards of the Open Geospatial Consortium (OGC), GeoServer allows significant functionalities for viewing and 
sharing of geographic objects and maps, as well as interoperability with a large number of commercial and free geoinformation systems and cartographic applications.

\begin{tabular}{|c|c|c|c|c|c|c|}
\hline$\square$ & 吅 & topp & taz_shapes & tasmania_state_boundaries & $\checkmark$ & EPSG:4326 \\
\hline$\square$ & นั & topp & taz_shapes & tasmania_water_bodies & $\checkmark$ & EPSG:4326 \\
\hline$\square$ & 口 & napusteni_kopovi_new & kopovi_v11_db & objekat_wgs84 & $\checkmark$ & EPSG:4326 \\
\hline$\square$ & ฉ & napusteni_kopovi_new & kopovi_v11_db & odobrenja_zahtevi_wgs84 & $\checkmark$ & EPSG:4326 \\
\hline$\square$ & ฉ & napusteni_kopovi_new & kopovi_v11_db & poligonidd_wgs84 & $\checkmark$ & EPSG:4326 \\
\hline$\ll$ & $<$ & $\gg \Rightarrow$ Results 1 to 2 & out of 22 items) & & & \\
\hline
\end{tabular}

Figure 9. The web GIS services published on GeoServer.

Open Geospatial Consortium (OGC) is the main international and industrial organization for standardization in the field of geospatial data. Web Map Service (WMS) is an OGC standard and at the same time the most popular and most widely used OGC Web service which specifies the communication between unrelated programs when sending or receiving pre-generated map imagery to users who have issued a request. Simply put, the WMS is a service by which the client can send a request to view a map from a server. This cartographic web service produces maps of georeferenced data by drawing them in the standard format for images (PNG, GIF, JPEG...) and publishes them via the Web [26]. Web Feature Service (WFS) enables communication at the level of the class itself and can be used for editing spatial data over the Web [27]

Cartographic web services are also available as Keyhole Markup Language (KML), which means that any application that reads KML, such as ArcGIS Explorer, ArcGlobe, and Google Earth, can read and interpret these services [28].

For user support and system errors reporting a tool based on Bugzilla [29] is used, customized and maintained by the Faculty of Mining and Geology [12]. The user has the option to search the list of topics similar to the current problem, and report a new problem. It is necessary to define a title for the error, give a brief description and select one of the errors categories, e.g., error in the application, error in the data, errors with suggestions for application upgrade, etc., while the screenshot with the error message can optionally be added. When an administrator solves the problem, an email is automatically sent to the user with the information that the error is corrected.

\section{Conclusions}

In this paper we presented the results of the strategic project Cadastre of Abandoned Mines on the Territory of the Autonomous Province of Vojvodina and Accompanying Database realized by University of Belgrade, Faculty of Mining and Geology, for the Provincial Secretariat for Energy and Mineral Resources of Vojvodina, and pointed out the usefulness, practical value and advantage of using WebGIS applications for accomplishing this task. The main reason for the realization of this project stemmed from the necessity of ensuring secure and reliable systematized data necessary for reclamation of all abandoned mines in Vojvodina, including national parks and other protected areas, in accordance with the existing legislation. The WebGIS application Kanakov, which is publicly available and offers access to a geodatabase containing administrative and spatial data for abandoned mines in Vojvodina, was developed using the state of the art information technology. A simple search panel enables retrieval of abandoned mines, and a systematized database is available that for the first time brought together all the available data on abandoned mines in the territory of Vojvodina, and as such can serve as a model for similar bases on the territory of the Republic of Serbia.

The project activities preformed within the development of the Cadastre of Abandoned Mines in Vojvodina and the accompanying WebGIS application were complex and multidisciplinary, involving a team of experts from the geological, mining, economic, ecologic, informatics, mathematics and 
other domains. Special attention was given to securing a high level and quality of project work, both regarding the quality of content, namely data and information, but also regarding the quality of structural relations among data, as well as quality of user interface featuring easy and simple search and display od structured data. The application aspects are multiple, and relate not only to the relevant sectors of mining and geology, but also to economic, urban planning, spatial planning, agriculture, hydrology, ecology, safety and other sectors. Such a broad application base points to the main directions of further development and upgrading of the database and WebGIS application developed within the project. The aim is to secure their full and active application within mineral resource management, ecology management, energy generation, but also management within official bodies, responsible for legislative legal, control and monitoring activities in realization of the mineral strategy, mineral policy and the concept of sustainable development in the mineral industry of Serbia.

Acknowledgments: This research was supported by the Serbian Ministry of Education and Science under the grant \#TR 33039 and Republic of Serbia Autonomous Province of Vojvodina Provincial Secretariat for Energy and Mineral Resources under grant "Cadastre of abandoned mines in the territory of AP Vojvodina".

Author Contributions: Ranka Stanković contributed database design and software development; Nikola Vulović contributed WebGIS development; Nikola Lilić contributed design of abandoned mines cadastre; Ivan Obradović contributed method of analytical hierarchy process; Radule Tošović contributed analysis of economic geology and Milica Pešić-Georgiadis contributed geoprocessing.

Conflicts of Interest: The authors declare no conflict of interest. The founding institutions had no role in the research; in the analyses of data; in the system development; in the writing of the manuscript, and in the decision to publish the results.

\section{Abbreviations}

The following abbreviations are used in this manuscript:

$\begin{array}{ll}\text { WebGIS } & \text { Web Geographical Information Systems } \\ \text { AHP } & \text { Analytic Hierarchy Process } \\ \text { GIS } & \text { Geographical Information Systems } \\ \text { KML } & \text { Keyhole Markup Language } \\ \text { WMS } & \text { Web Map Service } \\ \text { WFS } & \text { Web Feature Service } \\ \text { CASE } & \text { Computer-Aided Software Engineering } \\ \text { UML } & \text { Unified Modeling Language }\end{array}$

\section{References}

1. Hall, A.; Scott, J.A.; Shang, H. Geothermal energy recovery from underground mines. Renew. Sustain. Energy Rev. 2011, 15, 916-924. [CrossRef]

2. Clarke Energy, Abandoned Mine Methane Gas (AMM). Available online: https://www.clarke-energy.com/ coal-gas/abandoned-mine-gas/ (accessed on 11 April 2015).

3. Díez, R.R.; Díaz-Aguado, M.B. Estimating Limits for the Geothermal Energy Potential of Abandoned Underground Coal Mines: A Simple Methodology. Energies 2014, 7, 4241-4260. [CrossRef]

4. Abandoned Mines Hold Potential to Capture Wind Energy. Available online: http://www.nrri.umn.edu/ news/pumpedhydro.htm (accessed on 11 April 2015).

5. Tošović, R. Management in Modern Conditions of Serbian Mineral Economy, in Monograph Mineral Resources Complex of Serbia Today: Challenges and Crossroads; Vujić, S., Ed.; Academy of Engineering Sciences of Serbia, Faculty of Mining and Geology, Serbian Chamber of Commerce: Belgrade, Serbia, 2010; pp. 411-434.

6. Developing Spatial Data Infrastructures: The SDI Cookbook, Version 2.0. Available online: http:// gsdiassociation.org/images/publications/cookbooks/SDI_Cookbook_GSDI_2004_ver2.pdf (accessed on 25 January 2014).

7. Cadastre of Abandoned Mines in AP Vojvodina. Available online: http:/ / kanakov.vojvodina.gov.rs (accessed on 11 April 2015).

8. Ramm, F.; Topf, J.; Chilton, D. OpenStreet Map: Using and Enhancing the Free Map of the World, 1st ed.; UIT Cambridge Ltd.: Cambridge, UK, 2010.

9. OpenStreetMap. Available online: https://www.openstreetmap.org (accessed on 11 April 2015). 
10. ArcGIS REST Services Directory. Available online: http://services.arcgisonline.com (accessed on 11 April 2015).

11. Stanković, R.; Vulović, N.; Tošović, R.; Pešić-Georgiadis, M.; Lilić, N.; Obradović, I. Webgis Decision Support System for Management of Abandoned Mines. In Proceedings of the 5th International Symposium Mining and Environmental Protection, Vrdnik, Serbia, 10-13 June 2015; pp. 400-406.

12. RGF (Faculty of Mining and Geology) Bugzilla. Available online: http:/ / bugzilla.rgf.bg.ac.rs (accessed on 11 June 2015).

13. Ishizaka, A.; Labib, A. Analytic Hierarchy Process and Expert Choice: Benefits and Limitations; University of Portsmouth, Portsmouth Business School: Portsmouth, UK, 2009; pp. 201-220.

14. The Map of Groundwater Vulnerability of Serbia. Available online: http://geoliss.mre.gov.rs/hidro/ KartaUgrPodVodWeb/OpisKarteUgrozenosti.htm (accessed on 1 October 2014).

15. KaNaKoV guidelines. Available online: http://kanakov.vojvodina.gov.rs/uputstvo/uputstvo.pdf (accessed on 11 June 2015).

16. Saaty, R. The Analytic Hierarchy Process (AHP) for Decision Making. Pittsburgh: Creative Decisions Foundation, 2003. Available online: http://www.croce.ggf.br/dados/Tutorial\%20superdecisons.pdf (accessed on 11 April 2015).

17. Kardi, T. Analytic Hierarchy Process (AHP) Tutorial. Revoledu.com. Available online: http://people. revoledu.com/kardi/tutorial/AHP/AHP.htm (accessed on 1 April 2015).

18. Metadata Implementing Rules: Technical Guidelines based on EN ISO 19115 and EN ISO 19119, 2013. Available online: http://inspire.ec.europa.eu/documents/Metadata/MD_IR_and_ISO_20131029.pdf (accessed on 11 April 2015).

19. Infrastructure for Spatial Information in Europe (INSPIRE). Data Specification on Mineral Resources; European Commission Joint Research Centre. Available online: http://inspire.ec.europa.eu/documents/ Data_Specifications/INSPIRE_DataSpecification_MR_v3.0rc3.pdf (accessed on 11 April 2015).

20. The Interagency Appalachian Coal Mining Geographic Information System (GeoMine) Pilot Project Report. Available online: http://www.tips.osmre.gov/Geospatial/GEOMINE/FinalReport.pdf (accessed on 11 April 2015).

21. Office of Surface Mining Reclamation and Enforcement U.S. Department of the Interior Abandoned Mine Land Inventory System (e-AMLIS). Available online: http://www.osmre.gov/programs/AMLIS.shtm (accessed on 11 April 2015).

22. U.S. Geoscience Information Network (USGIN), Abandoned Mines Schema, URL. Available online: http: //schemas.usgin.org/models/ (accessed on 11 April 2015).

23. Upper Midwest Environmental Sciences Center, USGS, Ohio Valley Abandoned Mine Lands, URL. Available online: http://www.umesc.usgs.gov/management/dss/ohio_valley.html\#data (accessed on 11 April 2015).

24. Zakon o Rudarstvu i Geološkim istraživanjima, "Službeni glasnik RS”, br. 101/2015, The Law on Mining and Geological Exploration, "The Official Gazette RS", No. 101/2015) of 2015. Available online: http: //www.mre.gov.rs/doc/geologija-rudarstvo/zakon\%20o\%20rudarstvu10.12.pdf (accessed on 1 April 2015).

25. Stanković, R.; Kitanović, O.; Trivić, B.; Blagojević, B.; Prodanović, J. Gis Application, The Management and Administration of Exploratory and Exploitation Permit. In Proceedings of the 3rd International Symposium Energy Mining, Apatin, Serbia, 8-11 September 2010.

26. Geographic Information-Ubiquitous Public Access. Available online: https://www.iso.org/obp/ui/\#iso: std:iso:19154:ed-1:v1:en (accessed on 11 April 2015).

27. Geographic Information-Web Feature Service. Available online: https://www.iso.org/obp/ui/\#iso:std:iso: 19142:ed-1:v1:en (accessed on 11 April 2015).

28. Keyhole Markup Language. Available online: https://developers.google.com $/ \mathrm{kml}$ (accessed on 11 April 2015).

29. Bugzilla: Server Software for IT Development Management. Available online: https://www.bugzilla.org (accessed on 1 October 2014).

(C) 2016 by the authors; licensee MDPI, Basel, Switzerland. This article is an open access article distributed under the terms and conditions of the Creative Commons Attribution (CC-BY) license (http:/ / creativecommons.org/licenses/by/4.0/). 